\title{
Budget cuts threaten Israeli science jobs
}

Jerusalem. Government-funded research jobs for immigrant scientists from the former Soviet Union may fall victim to the new Israeli government's determination to slash its budget, according to scientists lobbying for subsidies to fund such posts.

Last week, the cabinet rejected a proposal from the Finance Ministry to eliminate funding for programmes that support immigrants working on university and private-sector research teams. But it stipulated that any expansion of these programmes would have to come out of the existing budget of the Ministry of Absorption, which is responsible for accommodating immigrants from the Soviet Union.

The cabinet also decided to set up a committee to decide whether current and proposed science job-creation programmes are "essential" and "worthwhile". A spokesman for Yuli Edelstein, the Minister of Absorption, called the cabinet decision a "victory", as it preserved US\$1 million in job subsidies approved before the election by the previous Labor government. Both Edelstein and Natan Scharansky, the Minister of Industry

\section{Private universities in Japan win grant boost}

Tokyo. Twenty-two of Japan's private universities are to receive generous "hightech research centre" grants worth an average of about $¥ 1$ billion (US\$9 million) under a new government scheme.

Apart from a handful of outstanding institutions, such as Waseda, Keio and Tokai universities, Japan's 410 private universities have not developed strong reputations for research, partly because they do not receive the same level of financial support for such work as the 98 national universities.

The new programme is intended to help redress the imbalance. The grant-winners were selected from 78 applications from 55 institutions. Half of the grants will go towards biological and medical research, and the others will support projects in information science, engineering and other sciences, with the emphasis on basic rather than applied research.

The Ministry of Education, Science and Culture has set aside $¥ 4.7$ billion in the current fiscal year, which began on 1 April, for buildings and facilities for the programme. This sum will be supplemented by additional grants from the ministry and the Japan Society for Promotion of Science, which will require matching funds from the private universities' own resources.

Details of the research programmes have yet to be mapped out; a ministry committee selected the winning applications merely on the basis of a brief summary of proposed research

Stephen Barker and Commerce, belong to Yisra'el ba-Aliya, a political party representing the interests of immigrants from the former Soviet Union.

But reactions from Israeli scientists who support the subsidies have ranged from puzzlement to exasperation. The coalition agreement signed by Yisra'el ba-Aliya with the Likud party of the prime minister, Benyamin Netanyahu, explicitly promises funding for existing programmes and to examine the possibility of expanding them.

Nathan Patlas, assistant professor of anatomy at the Hadassah Medical School of the Hebrew University of Jerusalem, and coordinator of immigrant scientists for Yisra'el ba-Aliya, says he has been told by Edelstein and Scharansky that the government's budget cuts meant that there would be no money for subsidies. "The immigrant scientists are very worried," he says.

Jobs for scientists became a political issue as a result of the mass immigration that occurred at the beginning of the decade, when more than half a million people arrived in Israel from the Soviet Union. Among them were 12,000 scientists - more than Israel itself had produced since independence in 1947.

The universities offered faculty positions to 180 of the top-flight newcomers. About 2,000 others were accepted, over the course of several years, joining research teams led by Israeli academics. The Ministry of Absorption provided minimal salaries for three years, hoping the scientists would then be able to find jobs in the private sector.

But not all university officials support the

subsidies. Amnon Pazy, professor of mathematics at the Hebrew University of Jerusalem, and chairman of the Planning and Grants Commission, which allocates funding to universities, fears that the costs will be passed on to the universities, and is concerned that the immigrants might end up as cheap research assistants.

Even with the help of these programmes, claims Yakov Faitelson, director-general of the Israel Association of Immigrant Scientists, 70 per cent of the immigrant researchers were left without work, or had to work outside their profession. Over the past year, as the three-year grants began to run out, the immigrants faced the loss of their jobs.

Dan Huppert, professor of physical chemistry, and three colleagues at Tel Aviv University, proposed to the government that it should subsidize lifetime positions for 400 of the most valued researchers. This idea was adopted last May by the government of the former prime minister, Shimon Peres.

Huppert's group also proposed programmes that would subsidize many more jobs in the academic and private sectors. In the wake of last May's elections, he and his colleagues had hoped that Yisra'el ba-Aliya would use its political clout in the new government to get these programmes funded.

But with Netanyahu determined to slash the national budget, it is not clear that the government will continue to fund even the existing programmes beyond this year.

Haim Watzman

\section{Heat turned up on climate author}

Washington. Benjamin Santer, the lead author of a controversial chapter of the Second Assessment Report of the Intergovernmental Panel on Climate Change (IPCC), and a climate scientist at the Lawrence Livermore National Laboratory in California, has come under attack by a prominent US congressman for his role in modifying the chapter's contents.

Dana Rohrabacher, the chair of the energy and environment subcommittee of the House of Representatives Science Committee, has written to Hazel O'Leary, the energy secretary, demanding information about Department of Energy (DOE) funding for the work of Santer and all other IPCC authors. He also wants the DOE to regulate their work for IPCC.

The letter repeats allegations made by the Global Climate Coalition (GCC), an industry-funded pressure group, that Santer broke the IPCC's own rules by modifying the content of Chapter 8 of the Second Assessment Report after it had been accepted by IPCC's science working group at Madrid last November (see Nature 381, 546; 1996).

Rohrabacher is a strident critic of the theory that global climate change is caused by man, which he has called "liberal claptrap". His subcommittee does not have direct power over research budgets, but it can influence policy by scrutinizing programmes it dislikes. In this case, the letter will send DOE officials on a lengthy paper chase after evidence to back up the work being done at its laboratories to support the IPCC process.

Sir John Houghton, formerly chief executive of the UK Meteorological Office and currently chairman of the Royal Commission on Environmental Pollution, who is co-chair of the IPCC science working group, backs Santer against this latest attack. "The allegations made are completely without foundation," he says. Colin Macilwain 